DOI: $\underline{\text { https://doi.org/10.24867/05OI03Popovic }}$

\title{
UNAPREĐENJE PROCESA POSLOVANJA PRIMENOM EDI STANDARDA ZA RAZMENU DOKUMENATA
}

\section{IMPROVEMENT OF THE BUSINESS OPERATION PROCEDURE APPLYING EDI STANDARD FOR DOCUMENT EXCHANGE}

\author{
Luka Popović, Fakultet tehničkih nauka, Novi Sad
}

\section{Oblast - INŽENJERSTVO INFORMACIONIH SISTEMA}

Kratak sadržaj - Tema ovog rada bazirana je na primeni elektronske razmene dokumenata. Prikazani su osnovni termini elektronske razmene dokumenata, dok je $u$ istraživačkom delu rada prikazana implementacija EDI razmene u kompaniji koja se bavi uslugom transporta $i$ skladištenja. Istraživanje je realizovano uz pomoć besplatnih FTP klijent aplikacija kao $i$ uz pomoć SAP ERP-a i SAP PI alata.

Ključne reči: Elektronska razmena podataka, SAP, $S A P$ PI, ERP, FTP

Abstract - The theme of this paper is based on the application of electronic document exchange. The basic terms of electronic document exchange are presented, while the research part of the paper shows the implementation of EDI exchange in a company engaged in transport and storage services. The research was conducted with the help of free FTP client applications as well as with SAP ERP and SAP PI tools.

Keywords: Electronic Data Interchange, SAP, SAP PI, ERP, IDOC, FTP

\section{UVOD}

U današnjem, digitalnom svetu kada je internet dostupan svima svaka kompanija koja želi uspešno da posluje na tržištu treba da ide u korak sa vremenom i da vrši konstantno unapređenje svojih poslovnih procesa. Kompanije su danas u mogućnosti da obavljaju međusobne transakcije putem interneta, i da vrše razmenu fajlova. Razmena fajlova putem interneta ubrzava procese, olakšava i unapređuje poslovanje kompanije. Postoje više načina za razmenu fajlova, u ovom radu će biti predstavljena primena $E D I$ (eng. Electronic Data Interchange) standarda za razmenu podataka.

Kako bi se sprečila razmena podataka u pisanoj formi između dva sistema, kompanije su počele sa primenom EDI razmene. EDI ili elektronsku razmena podataka predstavlja međunarodni standard koji omogućava razmenu poslovih dokumenata $\mathrm{u}$ digitalnom obliku sa malom verovatnoćom greške, uz maksimalnu brzinu i niske troškove.

\section{NAPOMENA:}

Ovaj rad proistekao je iz master rada čiji mentor je bio dr Darko Stefanović, vanr. prof.
Uspostavljanje EDI standarda dovodi do povećanja broja dokumenata koji se razmenjuju putem interneta. Primena EDI-a predstavlja pouzdan način razmene jer se smanjuje rizik od oštećenja ili gubitka dokumenata, što nije bio slučaj kod razmene podataka u papirnoj formi.

\section{OPIS KORIŠĆENIH TEHNOLOGIJA}

U ovom poglavlju će biti reči o osnovnim alatima i tehnologijama koji su neophodni za realizaciju procesa EDI razmene.

\subsection{Enterprice Resource Planning - ERP}

ERP (eng. Enterprise Resource Planning) sistem predstavlja posebno softversko rešenje koje preduzeću pomaže da bolje upravlja svojim resursima. Pod resursima se podrazumevaju: zaposleni, gotovina, osnovna sredstva, obrtna sredstva, hartije od vrednosti.

Ono što ERP razlikuje od ostalih poslovnih softverskih rešenja jeste integrisanost, odnosno posmatranje svih poslovnih funkcija preduzeća kao celinu. To predstavlja ujedno i njegovu glavnu prednost, i razlog zašto se kompanije odlučuju da ga koriste.

Takođe ERP predstavlja rešenje koje nije namenjeno samo velikim multinacionalnim kompanijama, već i srednjim i malim preduzećima. Još jedna od prednosti ovog sistema jeste što prati sve resurse u realnom vremenu i evidentira sve promene baš u trenutku kada se one stvarno i dogode [3]. Ovakav način poslovanja pomaže korisnicima da lakše sagledaju rast i razvoj kompanije. Danas, na tržištu ERP-a dominiraju tri kompanije SAP, Oracle i Microsoft. Uprkos konkurenciji SAP ima najveći tržišni deo u modernom poslovanju.

\subsubsection{Moduli u ERP-u}

Pojam modul se odnosi na pojedinačne komponente poslovnog sistema. Najkorišćeniji moduli ERP-a su: finansije i računovodstvo, nabavka, prodaja, ljudski resursi (eng. Human Resources-HR), upravljanje skladištenjem.

Finansije i računovodstvo -Neki od poslovnih aktivnosti ovog modula su glavna knjiga, upravljanje osnovnim sredstvima, upravljanje gotovinom, budžetiranje, upravljanje troškovima.

Nabavka - Ovaj modul obuhvata delove poslovanja kao što su upravljanje dobavljačima, planiranje nabavke, upravljanje magacinskim dokumentima. 
Prodaja - Ovaj modul obuhvata delove poslovanja koji se odnose na upravljanje kupcima, planiranje prodaje, upravljanje cenovnicima i popustima, kreditne limite.

HR - Ovaj modul obuhvata proces zapošljavanja kadrova, upravljanje ličnim podacima, upravljanje i evidentiranje odsustva, obračun zarada, obračun poreza i doprinosa.

Upravljanje skladištenjem - Ovaj modul obuhvata upravljanje magacinskim prostorima kompanije.

U zavisnosti od tipa poslovanja, veličine kompanije, broja zaposlenih variraju i moduli koje jedna kompanija koristi.

\subsection{Intermediate Document - IDOC}

IDOC (eng. Intermediate Document) predstavlja standardni format razmene koji se koristi za uvoz/izvoz podataka u/iz ERP sistema. Poslovni dokumenti kao što su fakture, isporuke, potvrde isporuka, stanje zaliha, matični podaci mogu se razmenjivati sa partnerima ili unutar kompanije upravo preko IDOC-a [2].

Kako bi uspešno identifikovao tip IDOC-a SAP koristi EDIFACT standard. EDIFACT standard je internacionalni standard koji obezbeđuje set standardnih poruka/formata koje omogućavaju razmenu elektronskih dokumenata [2]. Na osnovu EDIFACT standarda mozemo razlikovati tipove poruka kao što su DESADV (eng. Dispatch advice message), ORDERS (eng. Purchase order message), ORDRSP (eng. Purchase order response message), INVOICE (eng. Invoice message), INVRPT (eng. Inventory report message) [2].

\section{3. eXtensible Markup Language - XML}

XML (eng. eXtensible Markup Language) predstavlja standard za strukturu podataka koji se prenose putem interneta. Osnovna ideja prilikom razvoja $X M L$-a je bila da se napravi jezik koji će biti čitljiv. Osnovna sintaksa $X M L$-a je označavanje podataka uz pomoć tagova (eng. Tags) koji su lako razumljivi.

Osnovna prednost $X M L$-a jeste što se veoma lako može prilagoditi najrazličitijim oblastima, može se koristiti kod elektronske razmene podataka, skladištenje podataka [1]. $\mathrm{Na}$ internetu postoji veliki broj besplatnih alata za čitanje i pisanje dokumenata u $X M L$ formatu.

\subsection{File Transfer Protocol - FTP}

FTP (eng. File Transfer Protocol) predstavlja standardni protokol (eng. protocol) za prenos podataka na internetu i jedan je od najčešće korišćenih načina za razmenu datoteka. FTP protokol je zasnovan na klijent-server arhitekturi, za uspostavljanje sesije (eng. session) prema serveru nam je potreban FTP klijent (eng. client). za potrebe FTP klijent-a nam može poslužiti neka od mnogobrojnih besplatnih FTP klijent aplikacija. FTP klijent aplikacije predstavljaju grafički interfejs (eng. interface) koji sadrži niz FTP naredbi koje su raspoložive u okviru operativnih sistema.

Prilikom pokretanja FTP klijent-a potrebni su podaci o adresi servera URL (eng. Uniform Resource Locator) ili $I P$ adresa (eng. Internet Protocol address), kao i podaci za logovanje, odnosno korisničko ime (eng. Username) i lozinka (eng. Password).
Na FTP se komunikacija odvija putem dva posebna porta (eng. port). Komunikacija se sastoji od dve sesije, DTP (eng. Data Transfer Process) koja predstavlja sesiju za transfer, dok je druga PI (eng. Protocol Interpreter) koja ima ulogu kontrolne sesije [5].

\section{REALIZACIJA EDI RAZMENE}

Osnovni izazov u malim i srednjim kompanijama jeste vreme obrade informacija $\mathrm{i}$ isporuka proizvoda kupcima $\mathrm{u}$ dogovorenom vremenu. EDI razmena je realizovana u kompaniji koja se bavi uslugom transporta i logistike na tržištima zemlje i regiona, kao i na tržištu Afrike. U ovom poglavlju će biti objašnjen način realizacije EDI razmene. Osnovni razlog za uspostavljanje EDI razmene dokumenata jeste ubrzanje procesa dobijanja dokumenata, kako bi se smanjili mogući uticaji ljudske greške i kako bi se ubrzao proces same isporuke krajnjim kupcima.

Kako bi se lakše razumeo proces EDI razmene, na slici 1 . je prikazan dijagram toka aktivnosti.

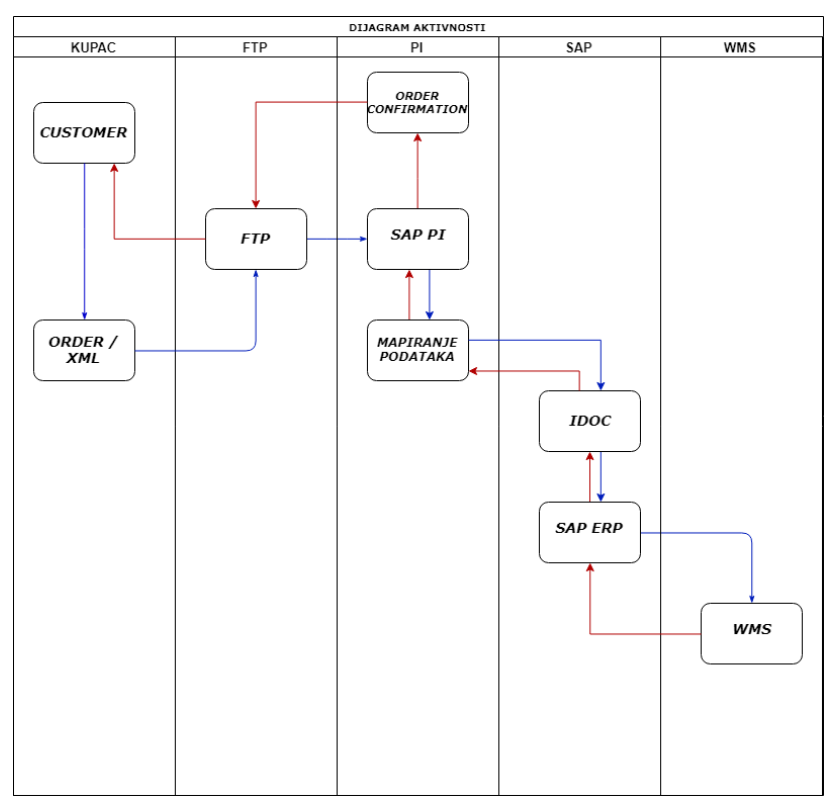

Slika 1. Dijagram toka aktivnosti EDI

EDI razmena u kompanijama se može podeliti u nekoliko faza:

1. Obrada $X M L$-a partnera

2. Mapiranje podataka

3. Kreiranje naloga za nabavku

4. Slanje potvrde ka klijentu

5. Prevoz robe

\subsection{Obrada $X M L$-a partnera}

Početna tačka kod procesa $E D I$ razmene dokumenata jeste principal/kupac koji kreira porudžbinu u svom ERP sistemu. Nakon kreiranja porudžbenice fajl se u odgovarajućem formatu (IDOC ili XML) upisuje na FTP lokaciju.

Nakon uspešnog snimanja fajla na FTP lokaciji, fajl se uz pomoć SAP PI (eng. SAP Proces Integration) čita i kreira se dokument prodaje u SAP-u.

SAP PI predstavlja NetWeaver platformu, program koji je pisan u Java programskom jeziku. Proces u okviru $S A P$ $P I$ se odvija u dva koraka, prvi je uspostavljanje 
komunikacije sa FTP serverom, dok je drugi korak čitanje fajla i mapiranje podataka sa $S A P$-om kako bi se kreirali odgovarajući dokumenti.

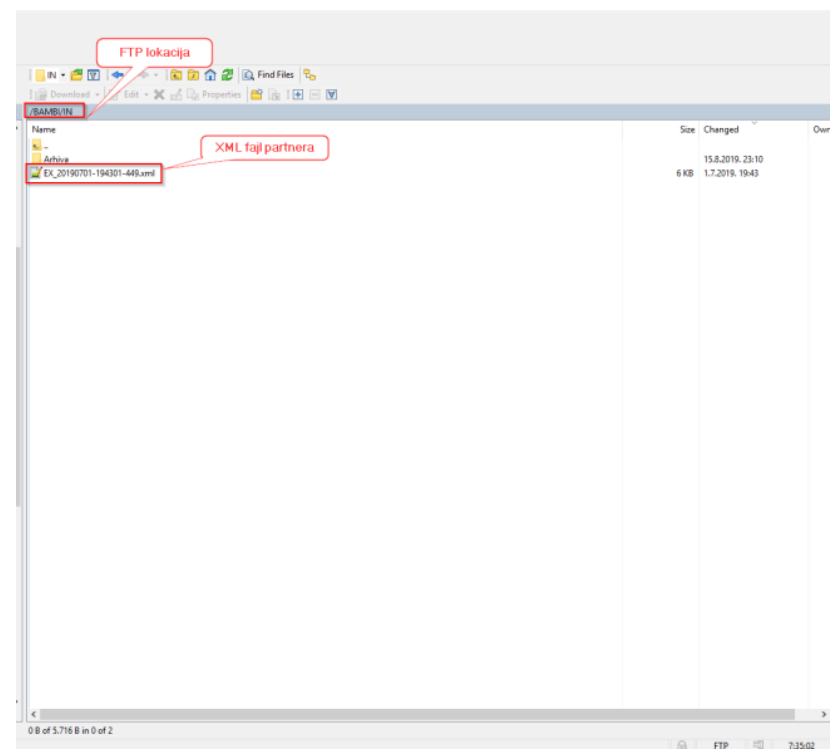

Slika 2. Prikaz snimljenog fajla na FTP-u

\subsection{Mapiranje podataka}

Mapiranje podataka se odvija uz pomoć SAP ESB (eng. Enterprise Services Builder) alata. Ovaj alat omogućava importovanje klijentove definicije fajla koja predstavlja $X S D$ šemu $X M L$ fajla, i povezivanje polja na odgovarajuća polja $I D O C$ strukture.

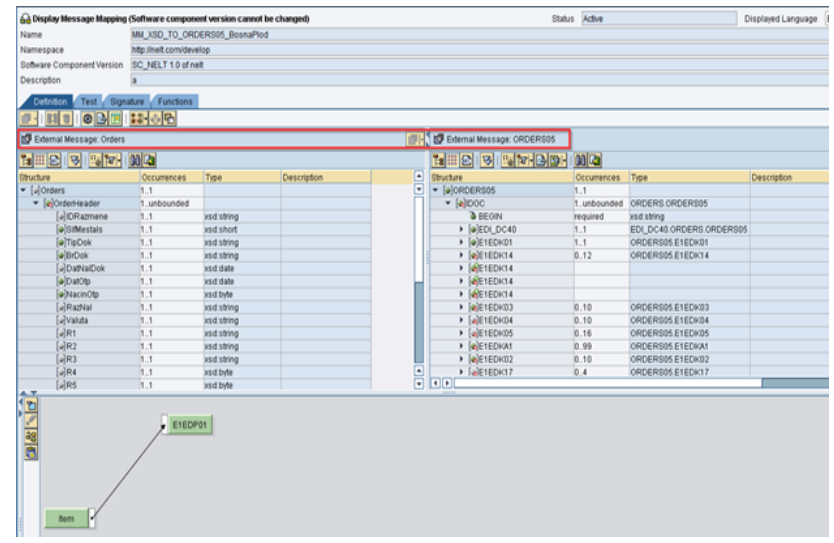

Slika 3. SAP ESB alat za mapiranje podataka

$\mathrm{Na}$ slici 2. se vidi prikaz alata za mapiranje podataka između SAP IDOC strukture i klijentovog XML fajla. Na levoj strani mapiranja je prikazana struktura $X M L$-a, vrednost svakog mapiranog polja na levoj strani će se preslikati u polje na desnoj strani koje predstavlja $S A P$ IDOC strukturu.

\subsection{Kreiranje naloga za nabavku}

Nakon uspešno mapiranja i kreirane porudžbenice, kreira se isporuka koja se iz $S A P$-a prosleđuje u WMS (eng. Warehouse Management System) gde se roba odvaja i pakuje. Nakon uspešno spakovane robe, roba se potvrđuje u WMS-u, isporuka sa potvrđenim količinama se vraća u SAP , knjiži se i kreira se fakturni dokument koji je potreban vozaču koji prevozi robu na mesto isporuke.

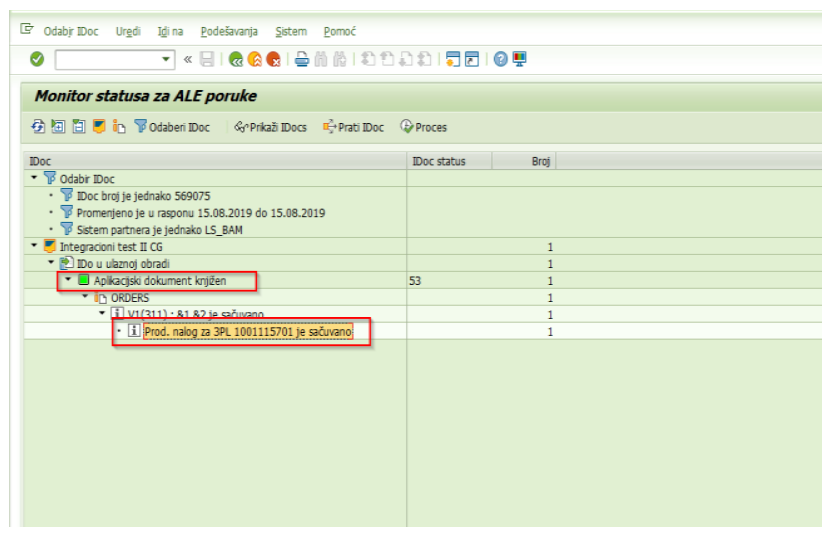

Slika 4. Potvrda kreiranog dokumenta u SAP-u

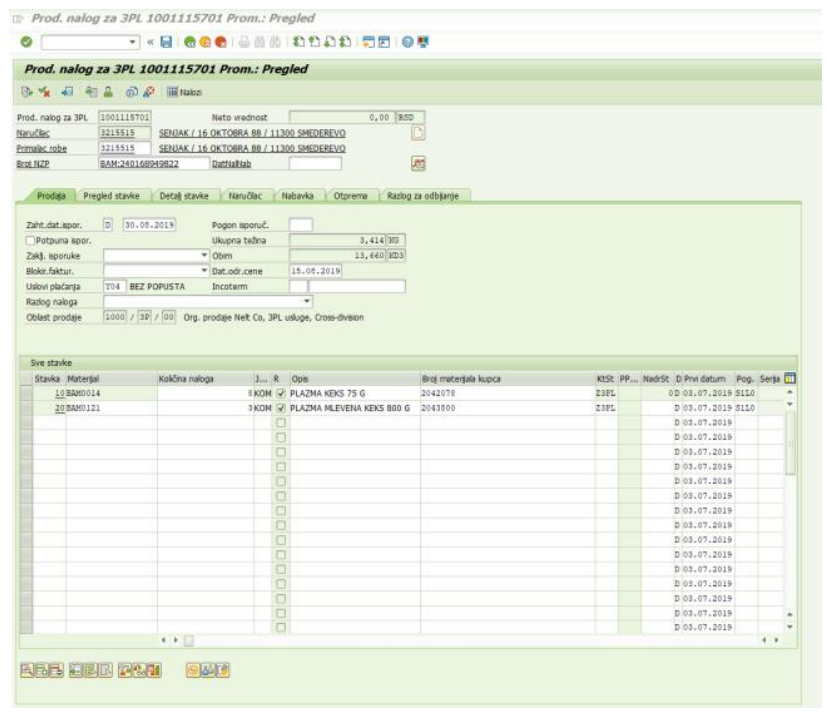

Slika 5. Prikaz kreiranog dokumenta u $S A P-u$

\subsection{Slanje potvrde ka klijentu}

Nakon fakturisanja isporuke preko $S A P \quad P I$ principalu/kupcu se šalje potvrda isporuke na FTP odakle on preuzima fajl i učitava ga u svoj ERP sistem. Dokument koji se vraća na FTP je potvrda principalu/kupcu, ovaj dokument sadrži podatke o tipu dokumenta, stvarno isporučenim količinama kao i tačnim datumom isporuke. $\mathrm{Na}$ osnovu ovog dokumenta principal/kupac podiže stanje svojih zaliha i stavlja robu na raspolaganje krajnjim kupcima.

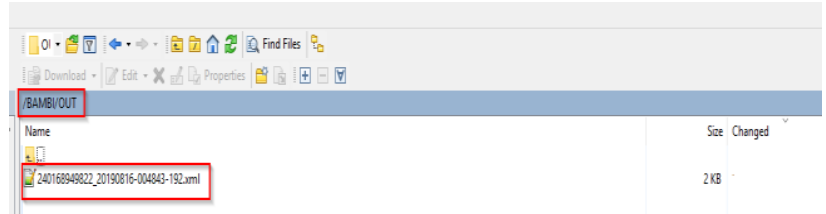

Slika 6. Prikaz izlaznog dokumenta iz SAP-a

\subsection{Prevoz robe}

Nakon što se dokument importuje u partnerovom ERP sistemu sledi isporuka robe. Na osnovu vraćenog 
dokumenta partner zna u kom trenutku će imati robu na stanju i u kojim količinama.

\section{PREDNOSTI I NEDOSTACI EDI RAZMENE}

U poglavlju 4 će biti navedeno nekoliko osnovih prednosti i nedostataka $E D I$ razmene.

\subsection{Prednosti $E D I$ razmene}

Brzina pristizanja fajlova - Osnovna prednost uspostavljanja EDI razmene je upravo u brzini pristizanja fajlova od principala/kupca. Fajlovi na FTP lokaciju stižu gotovo istovremeno od trenutka kad se isti kreiraju $\mathrm{u}$ sistemu principala/kupca i obrnuto.

Smanjivanje uticaja ljudskog faktora - Uspostavljanjem EDI razmene moguće ljudske greške se smanjuju na minimum. Proces je automatizovan i ništa se ne radi ručno već se fajlovi kreiraju direktno u ERP sistemima partnera koji vrše razmenu fajlova.

Uvid u pristigle fajlove - Svi fajlovi koji stignu od strane kupca/principala se arhiviraju. Ti fajlovi su u svakom trenutku dostupni, lako se može izvršiti pregled fajlova i provera da li je sve što je bilo poručeno stvarno i stiglo na zadatu lokaciju.

Smanjivanje troškova kompanije - Uspostavljanjem EDI razmene smanjuju se ukupni troškovi kompanija. Uz pomoć $E D I$ razmene podataka porudžbenice se kreiraju u ERP sistemu partnera i nije potrebno prisustvo prodavaca na terenu.

\subsection{Nedostaci $E D I$ razmene}

Nepotpuni podaci - Osnovni problem kod EDI razmene jeste što male ili srednje kompanije nisu u mogućnosti da isporuče sve neophodne podatke, to dovodi do teškoća pri određivanju pojedinih vrednosti u mapiranju podataka koje mogu da izazovu greške prilikom obrade fajlova.

Neispravnost podataka - Kompanije u svojim sistemima vrše promene koje nisu u skladu sa prvobitnim podešavanjima, to dovodi do kreiranja fajla sa neispravnim podacima. Neke od grešaka koje se često javljaju jesu da partneri otvaraju nove kupce, a prethodno nisu poslali obaveštenje da se novi kupac otvori i u ERP sistemu primaoca fajla. Primalac fajla nije u mogućnosti da obradi takav fajl i javljaju se greške u procesu mapiranja.

Otežano testiranje - Male i srednje kompanije nemaju razvijen test ERP sistem na kojem se mogu vršiti testiranja, već se sve radi na produkcionom okruženju. Iz tog razloga je testiranje pre puštanja u produkciju dosta otežano i zahteva mnogo više vremena što može dovesti do pomeranja rokova.

\section{ZAKLJUČAK}

Danas kad je internet dostupan svima, svaka kompanija koja želi uspešno da posluje mora da razmišlja o razmeni elektronskih fajlova.
Uspostavljanjem EDI razmene dobijamo dva sistema koja međusobno komuniciraju i na taj način se obezbeđuju maksimalni rezultati uz minimalne troškove. Postoji mnogo prednosti upotrebe EDI razmene, a jedna od glavnih jeste što je proces automatizovan i na ta način se smanjuje uticaj ljudskog faktora.

Iz celokupnog istraživanja dolazimo do zaključka da je EDI razmena bitan deo poslovne zajednice i da ima veliku ulogu u povećanju profitabilnosti organizacije. Bitno je napomenuti da mala preduzeća u našoj zemlji još uvek ne koriste sve pogodnosti koje $E D I$ razmena pruža, što bi u budućnosti trebalo unaprediti, prvenstveno širenjem svesti o rezultatima koji se mogu postići primenom ovog rešenja.

\section{LITERATURA}

[1] Yugen Du, Yonggang Li, "Integration by Virtual Web Service between XML/EDI and web application", Software Engineering Institute East China Normal University Shanghai, China

[2] Patrik Ajalin, Unai Briongos, Ari Kesäniemi, Outi Tarvainen, "SAP R/3 integration to RosattaNet processes using web service interface", T-86.301 Project Coure on ICT Enabled COmmerce \& T86.161 Special Topics In Information Technologz for Production II

[3] Helmut Klaus, Michael Rosemann and Guy G. Gable, "What is ERP?" Information System Management Research Center, Qzeensland University of Technology, Brisbane, Australia

[4] Paul Hart, Carol Saunders, "Power and Trust: Critical Factors in the Adoption and use of Electronic Data Interchange", Decision and Information Systems, Collage of Business, Florida Atlantic University, Boca Raton, Florida 33431-0991 Department of Menagment, Southern Illinois University, Carbondale, llinois 62901-4627

\section{Kratka biografija:}

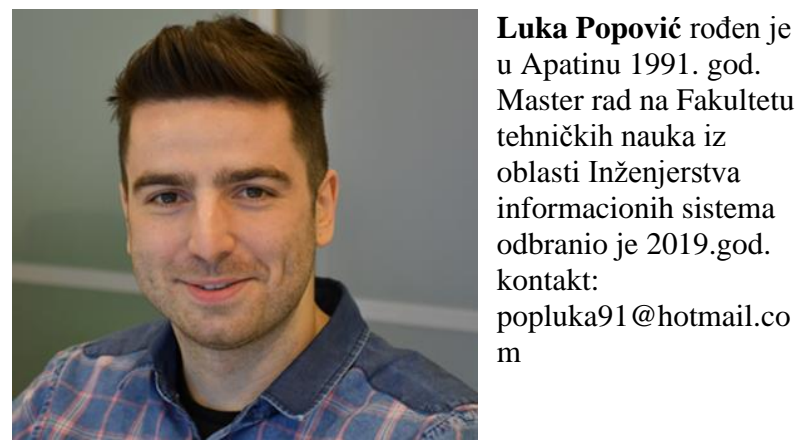

